\title{
Optimization of mango seed kernel oil extraction using response surface methodology
}

\author{
Fajriyati Mas'ud ${ }^{1,2, *}$, Meta Mahendradatta ${ }^{3}$, Amran Laga $^{3}$ and Zainal Zainal ${ }^{3}$ \\ ${ }^{1}$ Hasanuddin University, Makassar, 90245 South Sulawesi, Indonesia \\ 2 Department of Chemical Engineering, State Polytechnic of Ujung Pandang, Makassar, 90245 South Sulawesi, Indonesia \\ ${ }^{3}$ Department of Agricultural Technology, Hasanuddin University, Makassar, 90245 South Sulawesi, Indonesia
}

Received 9 June 2017 - Accepted 18 August 2017

\begin{abstract}
Response surface methodology (RSM) was applied to study the optimum condition of mango seed kernel oil (MSKO) extraction with n-hexane. In the present paper, for the first time, we provide an optimal condition of MSKO extraction to obtain the maximum of yield, total phenolic content (TPC) and vitamin E. The experiment was conducted using central composite design (CCD) consisted of twenty experimental points including six replicates of center points to study the effect of three independent variables: temperature, time and amount of n-hexane on dependent variables. Data were analyzed using Design-Expert 10 software. The result showed that the optimum condition of MSKO extraction were $54.19^{\circ} \mathrm{C}, 5.24 \mathrm{~h}$ and $224.23 \mathrm{~mL}$ of $\mathrm{n}$-hexane. In this condition MSKO have yield of $7.03 \%$, TPC of $67.77 \mathrm{mg}$ $\mathrm{GAE} / \mathrm{g}$ oil and vitamin E of $141.22 \mathrm{mg} / \mathrm{L}$. These results suggest that MSKO has potential as raw materials of food products oil-based and as a natural antioxidant of functional food and for use in food processing.
\end{abstract}

Keywords: mango seed kernel oil / oil extraction / total phenolic content / vitamin E / response surface methodology

\begin{abstract}
Résumé - Optimisation de l'extraction d'huile de noyau de mangue à l'aide de la méthodologie RSM. La méthodologie Response surface methodology (RSM) a été appliquée pour définir les conditions optimales d'extraction de l'huile de noyau de mangue avec du n-hexane. Dans le présent article, pour la première fois, est proposée une condition optimale d'extraction de l'huile de noyau de mangue afin d'optimiser le rendement, la teneur en phénols (total phenolic content ou TPC) et en vitamine E. L'expérience a été réalisée en utilisant plan d'expériences composite centré de vingt points expérimentaux avec six répétions de points centraux pour étudier l'effet de trois variables indépendantes : température, temps et quantité de n-hexane sur des variables dépendantes. Les données ont été analysées à l'aide du logiciel Design-Expert 10. Le résultat a montré que les conditions optimales d'extraction de l'huile de noyau de mangue étaient $54,19{ }^{\circ} \mathrm{C}, 5,24 \mathrm{~h}$ et $224,23 \mathrm{ml}$ de $\mathrm{n}$ hexane. Dans ces conditions, le rendement est de 7,03\%, la teneur TPC de 67,77 mg GAE/g d'huile et la concentration en vitamine E de 141,22 mg/L. Ces résultats soulignent le potentiel de l'huile de noyau de mangue en tant que matière première de produits alimentaires à base d'huile et en tant qu'antioxydant naturel des aliments fonctionnels et pour la transformation des aliments.
\end{abstract}

Mots clés : huile de noyau de mangue / extraction d'huile / phénols / vitamine E / RSM

\section{Introduction}

Mango, Mangifera indica, belongs to the family Anacardiaceae. It is a very popular fruit and often referred to as 'king of fruits' in the tropical world (Singh et al., 2002), but after consumed or used by the mango processing industry, mango seeds are generally only disposed of as waste (Puravankara

*Correspondence: fajri888@poliupg.ac.id et al., 2000; Kittiphoom, 2012). On the other hand, enough scientific information is available regarding the nutritional importance of mango waste, mainly of feeding ever-increasing human population. The issue of food insecurity in Asia and Africa in the coming 35-50years may lead to hunger and starvation (FAO, 2006). Mango seed account for 35\%-55\% of the fruit, depending on the variety (Bhalerao et al., 1989). MSKO may be defined as oil fraction extracted from stone of mango, it contains almost $15 \%$ of oil (Nzikou et al., 2010). Studies have disclosed that mango kernel is a potential source 
of wide range of bioactive compounds and antioxidants (Jafari et al., 2014). Cardio and hepatic protective effects, anticarcinogenic, anti-ageing effects of phenolic compounds are scientifically proven (Mohdaly et al., 2011). MSKO can be utilized for the preservation of fats and oils, improved oxidative stability of sunflower oil and tallow (Abdalla et al., 2007; Jafari et al., 2014).

Kittiphoom (2012) reported that MSKO consisted of about 44-48\% saturated fatty acid, it was dominated by stearic acid and $52-56 \%$ of unsaturated fatty acid, that could be used as a source of potential functional food ingredients because it contained high quality of oil which contained antioxidants in high concentration. MSKO has potential application in human foods (Kittiphoom and Sutasinee, 2013), potentially be used in the formulations of food products such as chocolate and biscuits as a natural nutritional additive due to its fatty acid composition and antioxidant activities (Jafari et al., 2014), and has been used in the cosmetics industry as an ingredient in soaps, shampoos and lotions because it is a good source of phenolic compounds (Soong and Barlow, 2004). Unfortunately, the massive nutritional and commercial potential of MSKO is not fully utilized. Toxicological assessment of MSKO was performed in multi generation breeding trials in weanling albino rats. Histopathology evaluation of organs did not reveal any abnormality. These results suggested that MSKO has no toxic effects (Rukmini and Vijayaraghavan, 1984; Agunbiade and Olanlokun, 2006). Analysis of cholesterol content of MSKO showed that it is free of cholesterol (Mostafa, 2013).

On the other hand, the extraction technique used to obtain high aggregate value compound from natural products is crucial for product quality (Kittiphoom and Sutasinee, 2013). The solvent extraction may be affected by various factors such as temperature, time, and amount of solvent. When many factors and interactions may affect a desired response, the RSM is an effective tool to find the optimal conditions for process (Stroescu et al., 2013). RSM is very popular for optimization solid-liquid extraction in recent years (Liu et al., 2009; Samaram et al., 2015). RSM is a statistical technique used to design experiments to obtain relevant information in the shortest possible time at the lowest cost. Basic principle of RSM is to relate product properties to regression equations that describe inter-relations between input parameters and product properties (Giovanni, 1983; Montgomery, 1984). Its use leads to the rapid and efficient development of new and improved products and processes. As the extraction is generally a multiparameter process, selection and optimization of the experimental conditions represents a critical step in the development of MSKO extraction methods. Previous studies showed that temperature, time and amount of solvent were the main parameters affecting the extraction yield from different sources (Li et al., 2012; Goula, 2013; Minjares-Fuentes et al., 2014). These parameters also had a significant influence on the endogenous bioactive compounds, such as certain from the TPC (Rodrigues et al., 2008; Ghafoor et al., 2009; Wang et al., 2013; Sahin and Samli, 2013; Chanioti et al., 2016).

Related to edible oil, the most important contribution of vegetable oils is its tocopherols, which is commonly and collectively referred to as "vitamin E". Vegetable oils contain high concentration of vitamin E (Bauernfeind and Desai, 1977) and could provide most daily dietary vitamin $\mathrm{E}$ requirement (Desai et al., 1980). The term of vitamin $\mathrm{E}$ is used to describe a group of eight molecules of related structure in which, chemical and biological activities are mostly dominated by $\alpha$-tocopherol (Brigelius-Flohé and Traber, 1999; Schneider, 2005). It occurs in the form of eight stereoisomers, four tocopherols $(\alpha, \beta, \gamma, \delta)$, and four tocotrienols $(\alpha, \beta, \gamma, \delta)$ (Pascual et al., 2013). Vitamin $E$ is a nutraceutical compound that have attracted researchers and food manufacturers due to its antioxidant and non-antioxidant biological activities (Mayer et al., 2013; Yang and McClements, 2013). Tocols are able to reduce lipid peroxidation and lipid risk factors, in this case elevated LDL cholesterol levels and platelet aggregation display anti-inflammatory properties and show anti-carcinogenic and cardiovascular protective effects (Tiwari and Cummins, 2009).

Based on reports of existing research results, in the present study, for the first time, RSM was employed to standardise the parameters (temperature, time and amount of n-hexane) for maximum yield, TPC and vitamin E of MSKO extraction. The aim of this study was to optimize the solvent extraction of MSKO with n-hexane in terms of yield, TPC and vitamin E applying the RSM technique and considering the extraction temperature, time and amount of n-hexane as variables.

\section{Materials and methods}

Arumanis mango, a local mango in Indonesia, as samples were obtained from South Sulawesi and harvested in September to November 2016. All chemical were from Merck, Germany. Standard of $\alpha$-tocopherol from SigmaAldrich Co. Preparation of MSK according to Mahale and Goswami-Giri (2011) with minor modification. The seeds were washed, and the kernel enclosed in the hard cover was separated manually. The kernels were dried in the oven at $50{ }^{\circ} \mathrm{C}$ for $12 \mathrm{~h}$ to a constant weight in order to reduce its moisture content. Separation of thin cover from the kernel was carried out using tray to blow away the cover in order to achieve very high yield. Stainless steel grinder was used to powdered form, sealed in a plastic container and stored in a freezer until extraction to prevention of its oxidation.

RSM was used to optimize the MSKO extraction process. At experimental unit, $50 \mathrm{~g}$ of MSK powder were weighed in the reactor $1.0 \mathrm{~L}$ four neck flasks, MSK was extracted with nhexane using a heating mantle connected with the thermometer setting, agitator on the top, speed of $200 \mathrm{rpm}$, residue was separated by centrifugation (refrigerated AX-521 centrifuge) at a speed of $3500 \mathrm{rpm}$ for $20 \mathrm{~min}$. The liquid part accommodated in the flask evaporator, solvents removed on a rotary evaporator Buchi R-215 incorporates vacuum Pomp $\mathrm{V}-700$. MSKO obtained was packaged in a dark glass bottle and stored in a freezer for analysis. The percentage oil yield was calculated as follows (Sani, 2014):

$$
\text { Oil yield }(\%)=\frac{\text { weight of oil }}{\text { weight of sample }} \times 100 .
$$

\subsection{Determination of total phenolic content (TPC) and vitamin $\mathrm{E}$ analysis}

The analysis method of TPC according to Brand-Williams et al. (1995), $0.25 \mathrm{~mL}$ MSKO were mixed with $2 \mathrm{~mL}$ of $10 \%$ 
Folin Ciocalteau reagent and $1.6 \mathrm{~mL}$ of $7.5 \% \mathrm{Na}_{2} \mathrm{CO}_{3}$ and left at room temperature for $30 \mathrm{~min}$. The mixing solution was measured an absorbance at $750 \mathrm{~nm}$ by ultraviolet-visible spectrophotometer (UV 1800, Shimadzu, Japan) and calculated as gallic acid equivalent. Analysis of vitamin E using standard $\alpha$-tocopherol. Preparation of standard vitamin E: $0.05 \mathrm{~g}$ dissolved in methanol-chloroform $(1: 1)$ at $100 \mathrm{~mL}$ flasks, and made respectively 100, 200, 300, 400, and $500 \mathrm{mg} /$ $\mathrm{L}$ in a $50 \mathrm{~mL}$ flask, homogenized by vortex, inserted in the vial GC-MS, the sample was injected automatically. Preparation of sample vitamin E: 0.012 g MSKO dissolved in $2 \mathrm{~mL}$ methanolchloroform (1:1), homogenized by vortex and inserted into the vial bottle GC-MS. The sample was injected automatically. Quantification of vitamin E was analyzed using GC-MS ultra Shimadzu QP2010, instrument uses column Rxi SH-5Sil MS (length $30 \mathrm{~m}$, diameter $\mathrm{x}$ thickness $0.25 \mathrm{~mm}$ ID 0:25 um df). Helium was used as a carrier gas at a pressure of $76.9 \mathrm{kps}$ with a flow of $14.0 \mathrm{~mL} / \mathrm{min}$, split ratio of $1: 10$. The initial temperature of the oven starting at $110^{\circ} \mathrm{C}$ and hold for 2 min until the oven temperature to $200^{\circ} \mathrm{C}$ with an isothermal increase of $10^{\circ} \mathrm{C} / \mathrm{min}$, a final temperature of $280^{\circ} \mathrm{C}$, hold for $9 \mathrm{~min}$ with an isothermal increase of $5^{\circ} \mathrm{C} / \mathrm{min}$, the total analysis time of $40 \mathrm{~min}$. Scan interval $45-450 \mathrm{~m} / \mathrm{z}$. Ion temperature $200{ }^{\circ} \mathrm{C}, 280{ }^{\circ} \mathrm{C}$ temperature interface.

\subsection{Experimental design for optimization and statistical analysis}

RSM was used to determine the optimum conditions for solvent extraction of MSKO. The variables used were extraction temperature $\left({ }^{\circ} \mathrm{C}, \mathrm{X}_{1}\right)$, time (hour, $\left.\mathrm{X}_{2}\right)$ and amount of $\mathrm{n}$-hexane $\left(\mathrm{mL}, \mathrm{X}_{3}\right)$. The complete design consisted of fourteen experiments and six replicates at the center point. Extraction yield, TPC and vitamin $\mathrm{E}$ of MSKO were selected as the responses for the combination of the independent variables. Statistic software (Design-Expert Version 10) was used for the regression analysis of the experimental data. The adequacy of each model was determined by evaluating the lack of fit and the coefficient of determination $\left(\mathrm{R}^{2}\right)$. The significance of each coefficient was determined by using the F-test obtained from the analysis of variance (ANOVA) that was generated. Regression coefficients were then used to generate response surfaces. 3D response surface graphs and profile for predicted values and desirability level for variables were plotted using the software. In order to verify the validity of the statistical models, additional verification experiments were subsequently performed. Verification of the optimum extraction condition was done by extraction of MSKO on a laboratory scale following the extraction condition suggested by the statistical models. For this verification, triplicate assenting experiments were carried out using the optimized parameters for yield, TPC and vitamin E of MSKO as response.

\section{Results and discussion}

The effects of $X_{1}, X_{2}$ and $X_{3}$ on yield, TPC and vitamin $\mathrm{E}$ of MSKO were studied during experimentation. The results showed that the yield, TPC and vitamin E of MSKO ranged from 5.16 to $7.08 \%, 31.81$ to $67.52 \mathrm{mg} \mathrm{GAE} / \mathrm{g}$ oil, and 100.25 to $140.27 \mathrm{mg} / \mathrm{L}$, respectively. The maximum yield, TPC and vitamin $\mathrm{E}$ of $\mathrm{MSKO}$ was found under the experimental conditions of $\mathrm{X}_{1}=54.19^{\circ} \mathrm{C}, \mathrm{X}_{2}=5.24 \mathrm{~h}$ and $\mathrm{X}_{3}=224.23 \mathrm{~mL}$, respectively. Maximum yield, TPC and vitamin E of MSKO under these conditions were $7.03 \%, 67.77 \mathrm{mg} \mathrm{GAE} / \mathrm{g}$ oil, and $141.22 \mathrm{mg} / \mathrm{L}$, respectively.

\subsection{Model fitting}

According to the result of ANOVA for yield, TPC and vitamin $\mathrm{E}$ of MSKO that the models are significant. The quality of the models developed was evaluated based on the correlation coefficient value. The $\mathrm{R}^{2}$ values of extraction yield, TPC and vitamin $E$ were $0.96,0.98$ and 0.97 , respectively, indicating that the models adequately represented the real relationship between the parameters chosen. Significance of different terms of each coefficient was determined using the $F$-value and $p$-value. According to Yolmeh et al. (2014), a large $F$-value and a small $p$ value would imply a more significant effect on the corresponding response variable. The actual quadratic equation of the yield, TPC and vitamin E of MSKO response are given in equations (2), (3) and (4), respectively.

$$
\begin{aligned}
\text { Yield }(\%) & =(-17.13)+0.26 \mathrm{X}_{1}+3.47 \mathrm{X}_{2}+0.07 \mathrm{X}_{3} \\
& -3.27 \mathrm{E}-003 \mathrm{X}_{1}^{2}-0.34 \mathrm{X}_{2}^{2} \\
& -1.18 \mathrm{E}-004 \mathrm{X}_{3}^{2}+0.02 \mathrm{X}_{1} \mathrm{X}_{2} \\
& +1.50 \mathrm{E}-005 \mathrm{X}_{1} \mathrm{X}_{3}-3.60 \mathrm{E}-003 \mathrm{X}_{2} \mathrm{X}_{3}
\end{aligned}
$$

$$
\begin{aligned}
\text { TPC }(\mathrm{mg} \mathrm{GAE} / \mathrm{g} \text { oil }) & =(-397.58)+5.91 \mathrm{X}_{1} \\
& +73.15 \mathrm{X}_{2}+1.002 \mathrm{X}_{3}-0.05 \mathrm{X}_{1}^{2} \\
& -5.81 \mathrm{X}_{2}^{2}-1.6 \mathrm{E}-003 \mathrm{X}_{3}^{2} \\
& -0.02 \mathrm{X}_{1} \mathrm{X}_{2}-8.28 \mathrm{E}-005 \mathrm{X}_{1} \mathrm{X}_{3} \\
& -0.05 \mathrm{X}_{2} \mathrm{X}_{3}
\end{aligned}
$$

$$
\begin{aligned}
\operatorname{Vitamin} \mathrm{E}(\mathrm{mg} / \mathrm{L}) & =(-255.92)+3.49 \mathrm{X}_{1}+77.15 \mathrm{X}_{2} \\
& +0.65 \mathrm{X}_{3}-0.03 \mathrm{X}_{1}^{2}-8.47 \mathrm{X}_{2}^{2} \\
& -2.07 \mathrm{E}-003 \mathrm{X}_{3}^{2}-0.10 \mathrm{X}_{1} \mathrm{X}_{2} \\
& -3.1300 \mathrm{E}-004 \mathrm{X}_{1} \mathrm{X}_{3}+0.09 \mathrm{X}_{2} \mathrm{X}_{3}
\end{aligned}
$$

\subsection{Interpretation of response surface model and contour plots}

The result of a statistical analysis showed that the fit model to describe the effect of $X_{1}, X_{2}, X_{3}$ for the yield is a quadratic model. The model $F$-value of 28.82 implies the model is significant. A positive value of coefficient $X_{1}, X_{2}, X_{3}$ in the equation (2) implies that $\mathrm{X}_{1}, \mathrm{X}_{2}, \mathrm{X}_{3}$ are effect on increasing the yield. Values of Prob $>F$ less than 0.0500 indicate model terms are significant (in this case $\mathrm{X}_{1}, \mathrm{X}_{2}, \mathrm{X}_{3}, \mathrm{X}_{1}^{2}, \mathrm{X}_{2}^{2}, \mathrm{X}_{3}^{2}$, $\mathrm{X}_{1} \mathrm{X}_{2}, \mathrm{X}_{2} \mathrm{X}_{3}$ ). The variables with the largest effect on yield were the linear terms of treatment $\left(X_{1}, X_{2}\right.$ and $\left.X_{3}\right)$, the quadratic term of treatment $\left(\mathrm{X}_{1}{ }^{2}, \mathrm{X}_{2}{ }^{2}\right.$ and $\left.\mathrm{X}_{3}{ }^{2}\right)$, followed by interaction between $X_{1}$ and $X_{2}$, and interaction between $X_{2}$ and $\mathrm{X}_{3}$. Values greater than 0.1000 indicate the model terms are not significant, so that interaction between $\mathrm{X}_{1}$ and $\mathrm{X}_{3}$ did not give any significant contribution to the yield of MSKO. The lack of fit $F$-value of 1.42 implies the lack of fit is not significant, 
which indicates that the model is suitable to describe the effect of treatment for the yield, and that the developed model is adequate for predicting the response. According to Bas and Boyaci (2007), the model will be considered appropriate if lack of fit value model is not significantly different at the level of specific $\alpha$.

The fit model to describe the effect of $X_{1}, X_{2}$ and $X_{3}$ for the TPC of MSKO is a quadratic model. A positive value of coefficient $X_{1}, X_{2}, X_{3}$ in the equation (3) implies that $X_{1}, X_{2}$ and $\mathrm{X}_{3}$ are effect on increasing the TPC. The model $F$-value of 45.08 and the low probability value $(p<0.0001)$ implies that the model is significant. The variables with the largest effect on TPC were the linear terms of treatment $\left(\mathrm{X}_{1}, \mathrm{X}_{2}, \mathrm{X}_{3}\right)$, the quadratic term of treatment $\left(\mathrm{X}_{1}^{2}, \mathrm{X}_{2}^{2}, \mathrm{X}_{3}^{2}\right)$, followed by interaction between $X_{2}$ and $X_{3}$. However, interaction term of $\mathrm{X}_{1} \mathrm{X}_{2}$ and $\mathrm{X}_{1} \mathrm{X}_{3}$ was not significant. The lack of fit $p$-value of 1.55 was non-significant, this indicates that the model is suitable to describe the effect of $\mathrm{X}_{1}, \mathrm{X}_{2}$ and $\mathrm{X}_{3}$ for the TPC, and that the developed model is adequate for predicting the response. These values would give a good fit to the mathematic model in equation (3).

The fit model to describe the effect of $\mathrm{X}_{1}, \mathrm{X}_{2}$ and $\mathrm{X}_{3}$ for the vitamin $\mathrm{E}$ of MSKO is a quadratic model. The model $F$-value of $35.11(p<0.0001)$ implies the model is significant. A positive value of coefficient $X_{1}, X_{2}$ and $X_{3}$ in the equation (4) implies that the treatment effects on increasing the vitamin $\mathrm{E}$. The variables with the largest effect on vitamin $E$ were $X_{3}$ and $\mathrm{X}_{2}^{2}$, followed by $\mathrm{X}_{1}, \mathrm{X}_{2}, \mathrm{X}_{1}^{2}, \mathrm{X}_{3}^{2}$, and $\mathrm{X}_{2} \mathrm{X}_{3}$. However, $\mathrm{X}_{1} \mathrm{X}_{2}$ and $X_{1} X_{3}$ were not significant. The lack of Fit $p$-value of 2.93 was non-significant $(p>0.05)$ which indicates that the model is suitable to describe the effect of $X_{1}, X_{2}$ and for the vitamin $E$, and that the developed model is adequate for predicting the response.

The sign "-" in front of all the first terms of the response equations (-17.13, -397.58 and -255.92$)$ does not have a significant meaning to the RSM model prediction. The signs "-" on the intercept are constants that will be meaningful to the approximate $\mathrm{X}_{1}, \mathrm{X}_{2}$, and $\mathrm{X}_{3}$ that are rational ( $\mathrm{X}$ values are not equal to zero). Intercept values do not always have to be interpreted, as often the range of $X_{1}, X_{2}$, and $X_{3}$ does not include zero as one of the observed values, so a negative intercepts does not matter as long as $\mathrm{X}_{1}, \mathrm{X}_{2}$, and $\mathrm{X}_{3}$ are not equal to zero (Dougherty, 2002; Mendenhall, 2011).

\subsection{Interpretation of contour plots}

The relationship between dependent and independent variables are illustrated in 3D representation of the response surfaces generated by the model for extraction yield, TPC and vitamin E of MSKO (Figs. 1-3, respectively). These plots are obtained depicting two variables within experimental range and keeping the third variable at a constant level. In order to gain a better understanding of the results of the yield of MSKO, the predicted model is presented in Figure 1 as the 3D plot. It can be seen the effect of $X_{1}$ and $X_{2}$ at a fixed $X_{3}$ on the yield MSKO. It is showed that the yield of MSKO had a maximum point. It appears that the results of the optimization conditions of MSKO extraction to obtain maximum yield indicate an increase. This means that the combination of $\mathrm{X}_{1}, \mathrm{X}_{2}$ and $\mathrm{X}_{3}$ are

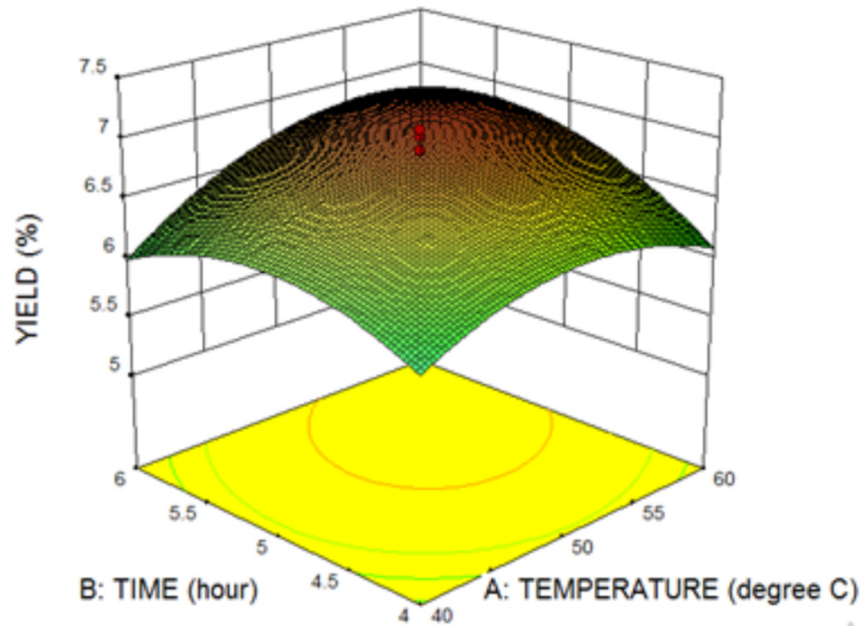

Fig. 1. Response surface plots of yield MSKO.

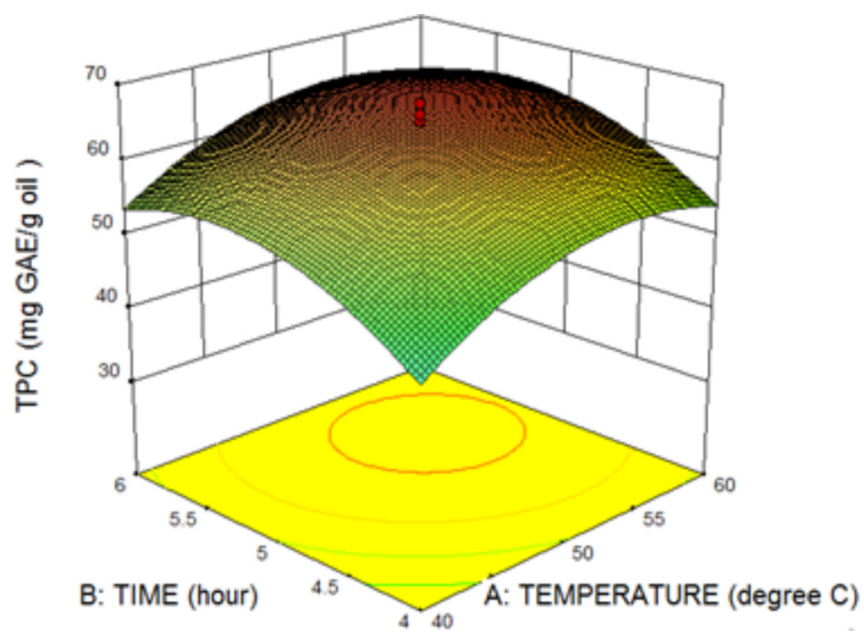

Fig. 2. Response surface plots of TPC MSKO.

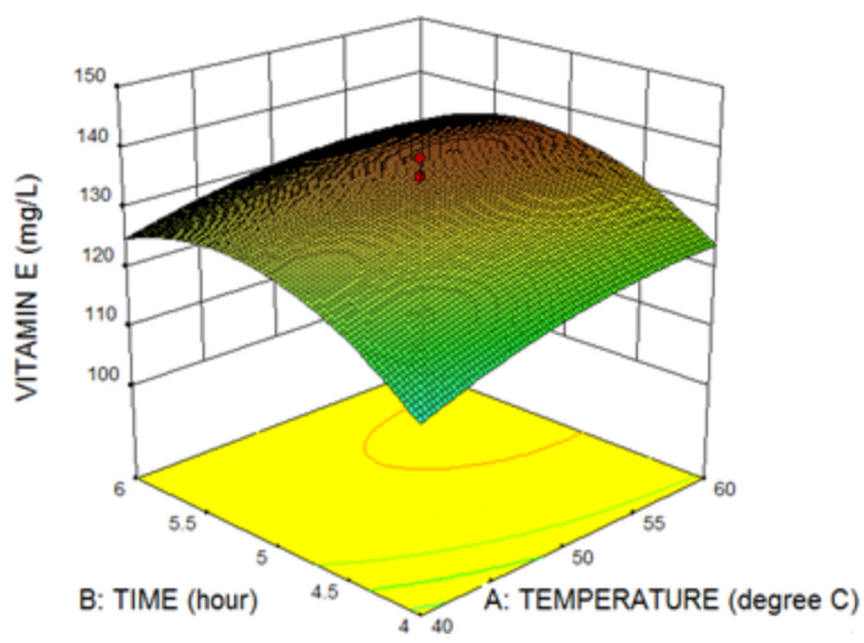

Fig. 3. Response surface plots of vitamin E MSKO. 
effect on increasing the yield of MSKO. The effect of $\mathrm{X}_{3}$ on yield is stronger than the effect of both $\mathrm{X}_{1}$ and $\mathrm{X}_{2}$. It is evident in the coefficient estimated of the ANOVA, larger value of $X_{3}$ (0.33) compared to value of $X_{1}(0.23)$, while the estimated coefficient of $\mathrm{X}_{2}$ is smaller (0.18).

The 3D plot corresponding to the effects of $X_{1}$ and $X_{2}$ on the TPC at a fixed $X_{3}(200 \mathrm{~mL})$ is shown in Figure 2. It is showed that the TPC had a maximum point. The combination of $X_{1}, X_{2}$ and $X_{3}$ are effect on increasing the TPC of MSKO. At $\mathrm{X}_{3}$ is constant $(200 \mathrm{~mL})$, the influence of $\mathrm{X}_{1}$ is slightly stronger than the effect of $X_{2}$ on increased of the TPC. It is evident in the coefficient estimated of the ANOVA, coefficient estimated of $\mathrm{X}_{1}(4.30)$ is slightly higher than the coefficient estimated of $\mathrm{X}_{2}$ (4.03). On the other hand, coefficient estimated of $\mathrm{X}_{3}(5.43)$ is higher than both coefficients estimated of $X_{1}$ and $X_{2}$, this means that the effect of $X_{3}$ is stronger than effect of both $X_{1}$ and $\mathrm{X}_{2}$ on TPC.

The 3D plot corresponding to the effect of $\mathrm{X}_{1}$ and $\mathrm{X}_{2}$ on the vitamin $E$ at a fixed $X_{3}(200 \mathrm{~mL})$ is shown in Figure 3. This result showed that the vitamin $\mathrm{E}$ had a maximum point. The combination of $X_{1}, X_{2}$ and $X_{3}$ were effect on increasing the vitamin $E$. At $X_{3}$ is constant $(200 \mathrm{~mL})$, the effect of $X_{1}$ slightly lower than the effect of $X_{2}$ on increasing the vitamin $E$. It is evident in the coefficient estimated of the ANOVA, coefficient estimated of $X_{1}$ (4.18) slightly lower than the coefficient estimated of $\mathrm{X}_{2}$ (4.73). On the other hand, coefficient estimated of $X_{3}$ (11.71) is higher than both coefficient estimated of $X_{1}$ and $\mathrm{X}_{2}$.

Based on the results of the optimum conditions that an increase of $\mathrm{X}_{1}$ from $40^{\circ} \mathrm{C}$ to $54.19^{\circ} \mathrm{C}$ and $\mathrm{X}_{2}$ from $5 \mathrm{~h}$ to $5.24 \mathrm{~h}$ (at fixed $\mathrm{X}_{3}$ of $200 \mathrm{~mL}$ ) promoted an increase in the yield, TPC and vitamin $E$ of MSKO. Further increase of $X_{1}$ up to $54.19^{\circ} \mathrm{C}$ and addition of $\mathrm{X}_{2}$ up to $5.24 \mathrm{~h}$ promoted a decrease in the yield, TPC and vitamin E of MSKO. An increase of $\mathrm{X}_{1}$ from 40 to $54.19^{\circ} \mathrm{C}$ and $\mathrm{X}_{3}$ from 150 to $224.23 \mathrm{~mL}$ (at fixed $\mathrm{X}_{2}$ of $5 \mathrm{~h}$ ) promoted an increase in the yield, TPC and vitamin E. Further, increase of $\mathrm{X}_{1}$ up to $54.19^{\circ} \mathrm{C}$ and addition $\mathrm{X}_{3}$ up to $224.23 \mathrm{~mL}$ promoted a decrease in the yield, TPC and vitamin E. The same phenomenon at an addition of $\mathrm{X}_{2}$ of $4 \mathrm{~h}$ to $5.24 \mathrm{~h}$ and $\mathrm{X}_{3}$ from $150 \mathrm{~mL}$ to $224.23 \mathrm{~mL}$ (at fixed $\mathrm{X}_{1}$ of $54.19^{\circ} \mathrm{C}$ ) promoted an increase in the yield, TPC, and vitamin E. Further, addition of $\mathrm{X}_{2}$ up to $5.24 \mathrm{~h}$ and addition $\mathrm{X}_{3}$ up to $224.23 \mathrm{~mL}$ promoted a decrease in the yield, TPC and vitamin E.

These results are in agreement with other oil studies. Abadi et al. (2014), reported that the amount of salmon liver oil yield is increased by increasing temperature from $50^{\circ} \mathrm{C}$ to $68^{\circ} \mathrm{C}$ in each of considered times, denoting direct impact of temperature increase on increasing percent of oil extraction, it is similar to effect of extraction time. Koleva and Simeonov (2014) and Stroescu et al. (2013) reported that temperature and solid-liquid ratio had the greatest influence on the oil yield. Mani et al. (2007) and Minjares-Fuentes et al. (2014) reported that by increasing the temperature of extraction, the yield of oil is maximized. The more time given to the seeds for contact with the solvent, the higher the extraction yield percentage (Elkhaleefa and Shigidi, 2015).

The linear relationship of temperature and solvent ratio to solid on the extraction of phenolic compound has also been reported by Cacace and Mazza, (2003). Rodrigues et al. (2008) reported that the greatest effect on TPC of extracts was promoted by the solid-liquid ratio and the temperature. Cacace and Mazza (2003) and Wang et al. (2013) reported that solidliquid ratio is the most significant parameter affecting of TPC. According to Ghafoor et al. (2009), the solubility of phenolic compounds increases with increasing of temperature and extraction time. Although the positive effect of higher temperature on the extraction yield, but the temperature cannot be increased indefinitely, because the stability of phenolic compounds and membrane denaturation can occur at temperature $>50^{\circ} \mathrm{C}$ (Schwartzberg and Chao, 1982; Cacace and Mazza, 2003).

Related to vitamin E, Pascual et al. (2013) reported the effect of temperature on vitamin $\mathrm{E}$, in this case against tocol contents in rice parboiling and cooking. They are reported that parboiling affected mostly vitamin $\mathrm{E}$, which presented an average loss of approximately $60 \%$ when compared to the initial level. Khatoon and Gopalakrishna (2004) already reported high losses of tocols after parboiling a single Indian commercial brown rice sample. Cooking caused a further loss of tocols and the final amounts were irrelevant in both cooked non-parboiled and parboiled rice. Kumar et al. (2006) have studied the effect of different cooking conditions (different rice-water ratios) on retention of tocols in rice bran and reported a variable retention of total tocols from 1 to $59 \%$ depending on the amount of water used.

Mango seed can be used as an alternative source of vitamin $\mathrm{E}$ which is also an antioxidant. Antioxidant vitamin has been reported to be able to reduce the oxidative processes that are important in the initiation of arthrosclerosis (Steinberg et al., 1989). A natural tocopherol mixture is used as an antioxidant up to $500 \mathrm{ppm}$ along with ascorbyl palmitate which enables to prolong antioxidant activity. At higher levels $(>1000 \mathrm{ppm})$ $\alpha$-tocopherol is thought to act as a pro-oxidant, the addition of $200 \pm 800 \mathrm{ppm}$ tocols in vegetable oils only exhibits limited effects. Hudson et al. (2000), who has study on rice bran oil reported that the isoforms of vitamin $\mathrm{E}$ and polyphenols in rice bran oils are bioactive components that are known to exhibit a variety of antioxidant activities that can be directly related to anticancer activity.

\subsection{Verification of optimum extraction condition of MSKO}

Triplicate experiments were carried out using the optimized parameters for each response for verification. It was aimed to prove that the optimum extraction condition solution suggested by the program provides yield, TPC and vitamin $\mathrm{E}$ of MSKO in accordance with the predicted values. The result showed that the average of yield, TPC and vitamin E were $7.22 \%, 70.67 \mathrm{mg} \mathrm{GAE} / \mathrm{g}$ oil and $141.37 \mathrm{mg} / \mathrm{L}$, respectively. The MSKO produced in the verification process showed that the average value of the yield, TPC and vitamin E were slightly higher than the predicted values. This indicates that the developed models were valid and adequate in their predictions and they can be used to optimize the extraction process of MSKO. These results suggest that the MSKO obtained from the verification process can be applied to extracting of MSKO, but it must be noted that succeeding higher MSKO yield at higher extraction temperature has limited industrial application because the bioactivity of MSKO might be imperiled. 


\section{Conclusions}

MSKO, an important by-product of mango and a rich source of phenolic and vitamin $\mathrm{E}$ as a bioactive compound was confirmed, and RSM was applied to determine the optimal extraction conditions of temperature, time, and amount of nhexane. The procedure was evaluated in terms of the oil extraction yield, TPC and vitamin E. The results of this study can be applied to obtain the optimum conditions of MSKO extraction, and can be applied in food industry. The results suggest that MSKO has potential as raw materials of food products oil-based and as a natural antioxidant of functional food and for use in food processing.

Acknowledgments. Thanks to the Directorate General of Higher Education of Indonesia for a doctoral grant that supports the funding of this study.

Conflicts of interest. The authors declare that they have no conflicts of interest in relation to this article.

\section{References}

Abadi FZK, Abolhasan A, Amir H. 2014. Evaluation and estimation of mass transfer parameters influencing salmon liver oil extraction. Indian J Nat Sci 5(27): 2083-2089.

Abdalla EM, Darwish SM, Ayad EHE, EL-Hamahmy RM. 2007. Egyptian mango by-product. Antioxidant and antimicrobial activities of extract and oil from mango seed kernel. Food Chem 103: $1141-1152$.

Agunbiade SO, Olanlokun JO. 2006. Studies on the nutritive values of the seed kernels of exotic and local mangoes. Biomed Biophys Res Asia 3: 122-125.

Bas D, Boyaci IH. 2007. Modelling and optimization I: Usability of response surface methodology. J Food Eng 78: 836-45.

Bauernfeind JS, Desai ID. 1977. The tocopherol content of food and influencing factors. Crit Rev Food Nutr 8: 337-382.

Bhalerao SD, Mulmuley GV, Anathakrishna SM, Potty VH. 1989. Wash and waste water management in food industry. Fruit and vegetable processing. Indian Food Packer 43(2): 5-11.

Brand-Williams W, Cuvelier ME, Berset C. 1995. Use of free radical method to evaluate antioxidant activity. LWT-Food Sci Technol 28: $25-30$

Brigelius-Flohé R, Traber MG. 1999. Vitamin E: function and metabolism, FASEB J 13: 1145-1155.

Cacace JE, Mazza G. 2003. Optimization of extraction of anthocyanin from black currants with aqueous ethanol. J Food Sci 68: 240 248.

Chanioti S, Siamandoura P, Tzia C. 2016. Evaluation of extracts prepared from olive oil by-products using microwave-assisted enzymatic extraction: effect of encapsulation on the stability of final products. Waste and biomass valorization. DOI: 10.1007/ s12649-475016-9533-1.

Desai ID, Swann MA, Garcia Tavares ML, Dutra de Oliveira BS, Duarte FAM, Dutra de Oliveira JE. 1980. Vitamin E status of agricultural migrant workers in Southern Brazil. Am J Clin Nutr 33: $2669-2673$

Dougherty C. 2002. Introduction to econometrics, 2nd ed. New York: Oxford University Press, pp. 13-14.

Elkhaleefa A, Shigidi I. 2015. Optimization of sesame oil extraction process conditions. Adv Chem Eng Sci 5: 305-310. https://doi. org/10.4236/aces.2015.53031.
FAO. 2006. The state of food insecurity in the world. http://www.fao. org/docrep/009/a0750e/a0750e00.htm. Accessed at 2014/01/08.

Ghafoor K, Choi YH, Jeon JY, Jo IH. 2009. Optimization of ultrasound-assisted extraction of phenolic compounds, antioxidants, and anthocyanins from grape (vitis vinifera) seeds. J Agric Food Chem 57: 4988-4994.

Giovanni M. 1983. Response surface methodology and product optimization. Food Technol 37(11): 41-45.

Goula A. 2013. Ultrasound-assisted extraction of pomegranate seed oil - Kinetic modeling. J Food Eng 117: 492-498.

Hudson EA, Dinh PA, Kokubun T, Simmonds MSJ, Gescher A. 2000. Characterization of potentially chemopreventive phenols in extracts of brown rice that inhibit the growth of human breast and colon cancer cells. Cancer Epidemiol Biomark Prev 9(11): $1163-1170$.

Jafari M, Gharachorloo M, Hemmaci AH. 2014. The stabilizing effect of three varieties of crude mango seed kernel oil on tallow. J Food Biosci Technol 4(1): 31-36.

Khatoon S, Gopalakrishna AG. 2004. Fat-soluble nutraceuticals and fatty acid composition of selected Indian rice varietas. $J$ Am Oil Chem Soc 81: 939-943.

Kittiphoom S. 2012. Utilization of mango seeds. Int Food Res $J 19$ (4): 1325-1335.

Kittiphoom S, Sutasinee S. 2013. Mango seed kernel oil and its physicochemical properties. Int Food Res J 20(3): 1145-1149.

Koleva V, Simeonov E. 2014. Solid liquid extraction of phenolic and flavonoid compounds from cotinus coggygria and concentration by nano-filtration. Chem Biochem Eng $Q$ 28(4): 545-551. DOI: 10.15255/CABEQ.2014.2006.

Kumar HGA, Khatoon S, Prabhakar DS, Krishna AGG. 2006. Effect of cooking of rice bran on the quality of extracted oil. J Food Lipids 13: 341-353.

Li T, Qu X, Zhang Q, Wang Z. 2012. Ultrasound-assisted extraction and profile characteristics of seed oil from Isatis indigotica Fort. Ind Crop Prod 35: 98-104.

Liu S, Yang F, Zhan C, Ji H, Hong P, Deng C. 2009. Optimization of process parameters for supercritical carbon dioxide extraction of Passiflora seed oil by response surface methodology. J Supercrit Fluids 48: 9-14.

Mahale SM, Goswami-Giri AS. 2011. Composition and characterization of refined oil compared with its crude oil from waste obtained from Mangifera indica. Asian J Res Chem 4: 14151419.

Mani S, Jaya S, Vadivambal R. 2007. Optimization of solvent extraction of Moringa (Moringa oleifera) seed kernel oil using response surface methodology. Food Bioprod Process 85: 328335.

Mayer S, Weiss J, McClements DJ. 2013. Vitamin E-enriched nanoemulsions formed by emulsion phase inversion: factors influencing droplet size and stability. J Colloid Interface Sci 402: 122-130. DOI: 10.1016/j.jcis.2013.04.016.

Mendenhall W. 2011. A second course in statistics: regression analysis, 7th ed. Upper Saddle River, New Jersey: Prentice Hall. 99 p.

Minjares-Fuentes R, Femeni A, Garau MC, Meza-Velázquez JA, Simala S, Rosselló C. 2014. Ultrasound-assisted extraction of pectin from grape pomace using citric acid: a response surface methodology approach. Carbohydr Polym 106: 179-189.

Mohdaly AA, Smetanska AI, Ramadan MF, Sarhan MA, Mahmoud A. 2011. Antioxidant potential of sesame (Sesamum indicum) cake extract in stabilization of sunflower and soybean oils. Ind Crop Prod 34: 952-959.

Montgomery DC. 1984. Design and analysis of experiments, Singapore: John Wiley \& Sons, Inc: 204-208. 
Mostafa UE. 2013. Phenolic compounds and antioxidant potential of mango peels and kernels (Mangifera indica L.) on the frying oil stability, lipid profile and activity of some antioxidant serum enzymes in rats. J Am Sci 9(11): 371-378.

Nzikou JM, Kimbonguila A, Matos L, et al. 2010. Extraction and characteristics of seed kernel oil from mango (Mangifera indica). RJ Environ Earth Sci 2: 31-35.

Pascual CSCI, Isabel LM, Fabiana K, Rosa MCB, José AN, Ursula MLM. 2013. Effects of parboiling, storage and cooking on the levels of tocopherols, tocotrienols and $\gamma$-oryzanol in brown rice (Oryza sativa L.) Food Res Int 50: 676-681.

Puravankara D, Boghra V, Sharma RS. 2000. Effect of antioxidant principles isolated from mango (Mangifera indica L) seed kernels on oxidative stability of buffalo ghee (butter-fat), J Sci Food Agric 80(4): 522-526. DOI: 10.1002/(SICI)1097-0010(200003) 80:4.522:AID-JSFA560.3.0.CO;2-R.

Rodrigues S, Pinto G, Fernandes F. 2008. Optimization of ultrasound extraction of phenolic compounds from coconut (Cocos nucifera) shell powder by response surface methodology. Ultrason Sonochemistry 15: 95-100.

Rukmini C, Vijayaraghavan M. 1984. Nutritional and toxicological evaluation of mango kernel oil. J Am Oil Chem Soc 61: 780-792.

Sahin S, Samli R. 2013. Optimization of olive leaf extract obtained by ultrasound-assisted extraction with response surface methodology. Ultrason Sonochemistry 20: 595-602.

Samaram S, Mirhosseini H, Tan C, Ghazali H, Bordbar S, Serjouie A. 2015. Optimisation of ultrasound-assisted extraction of oil from papaya seed by response surface methodology: oil recovery, radical scavenging antioxidant activity and oxidation stability. Food Chem 172: 7-17.

Sani I. 2014. Soxhlet extraction and physicochemical characterization of Mangifera indica L. Seed kernel oil. Research and Reviews: $J$ Food Dairy Tech 2(1): 20-24.
Schneider C. 2005. Chemistry and biology of vitamin E. Mol Nutr Food Res 49: 7-30. DOI: 10.1002/mnfr.200400049.

Schwartzberg HG, Chao RY. 1982. Solute diffusivities in leaching processes. Food Technol 2: 73-86.

Singh SK, Sharma HC, Singh SP. In vitro polyembryony in monoembryonic mango cultivars (Mangifera indica L.) In: Kapoor AC, ed. Sustainability of Hill Agriculture: emerging trends and possible solutions. New Delhi: Todays and Tomorrows Printers and Publishers, 2002. pp. 295-299.

Soong YY, Barlow PJ, Perera CO. 2004. A cocktail of phytonutrients: identification of polyphenols, phytosterol and tocopherols from mango seed kernel. IFTAnn meeting Lasvegas 12-16.

Steinberg D, Parthasarathy S, Carew TE, Khoo JC, Witztum JL. 1989. Beyond cholestrol: modification of low density lipoprotein that increase its atherogenicity. $N$ Engl J Med 320: 915-924.

Stroescu M, Stoica-Guzun A, Ghergu S, Chira N, Jipa I. 2013. Optimization of fatty acids extraction from Portulaca oleracea seed using response surface methodology. Ind Crops Prod 43: 405-411.

Tiwari U, Cummins E, 2009. Nutritional importance and effect of processing on tocols in cereals. Trends Food Sci Technol 20: 511-520.

Wang X, Wu Y, Chen G, Yue W, Liang Q, Wu Q. 2013. Optimisation of ultrasound assisted extraction of phenolic compounds from Sparganii rhizoma with response surface methodology. Ultrason Sonochemistry 20: 846-854.

Yang Y, DJ McClements. 2013. Vitamin E bio accessibility: influence of carrier oil type on digestion and release of emulsified $\alpha$-tocopherol acetate. Food Chem 141: 473-481. DOI: 10.1016/j. foodchem.2013.03.033.458.

Yolmeh M, Habibi NM, Farhoosh R. 2014. Optimization of ultrasound-assisted extraction of natural pigment from annatto seeds by response surface methodology (RSM). Food Chem 155: 319-324.

Cite this article as: Mas'ud F, Mahendradatta M, Laga A, Zainal Z. 2017. Optimization of mango seed kernel oil extraction using response surface methodology. OCL 24(5): D503. 